\title{
Analysis of Factors Affecting Kiwifruit Export
}

\author{
Wei $\mathrm{Xu}^{1,2 *}$ \\ ${ }^{1}$ Xi'an Tadffic Engineering Institute, Xi'an 710300, Shaanxi Province, China \\ ${ }^{2}$ Northwest A\&F University, Yang Ling 712100, Shaanxi Province, China
}

\begin{abstract}
The Trade Gravitation Model was used to empirically analyze the trade flows and directions of kiwifruit in 9 countries for 5 years. The results showed that the economic scale (GDP) and institutional arrangements of trading partners were significant factors. The scientific use of the Trade Gravitation Model can promote the smooth development of export trade.
\end{abstract}

\section{Introduction}

Tinbergen and Poyhonen first used the extended gravity model to study the issues of international trade. Empirical analysis believed that the bilateral trade flows between the two countries are directly proportional to the GDP, and inversely proportional to the distance of them. The reason is that the GDP of the exporting country reflects the potential production capacity of the country. To the importing country it reflects the potential demand capacity. The transportation cost between the two traders represented by the bilateral distance constitutes the trade between the two countries resistance. Later, many scholars began to empirically analyze more problems in the trade field by increasing the explanatory variables to expand the gravitational model. Hu Qiuguang et al. used the gravitational model to empirically analyze the trade flows and directions of aquatic products, and found that the economic scale, geographical distance and institutional arrangement of the two sides are the main factors to affect the trade. He Shufeng et al. used the stochastic frontier gravitational model to measure the trade potential of China and trading partner countries in the traditional trade environment and in the Arctic waterway environment. The results showed that there was a significant negative correlation between China's trade export efficiency and shipping distance. Gao Zhigang used the trade gravity model to analyze the trade potential between China and Central Asian countries. He believed that the distance between countries, economicdevelopment level and transportation cost were the main factors affecting exports and bilateral trade.Sun Jinyan analyzed the trade scale and complementarity between China and Australia, and used the trade association index and gravity model to estimate the trade potential between the two countries. He pointed out that the trade potential between China and Australia had not been fully exploited. There is still much room for improvement in cooperation. Therefore, the scientific trade gravity model is used to estimate the potential of the export trade of kiwifruit, in order to provide theoretical guidance for trade between countries.

\section{Model construction}

The basic form of the trade gravity model is as follows:

$$
T_{\mathrm{ij}}=A\left(Y_{\mathrm{i}} Y_{\mathrm{j}}\right) / D_{\mathrm{ij}}
$$

$\mathrm{i}$ and $\mathrm{j}$ represent countries $\mathrm{i}$ and $\mathrm{j}$, respectively; $T_{\mathrm{ij}}$ is the bilateral trade volume between the two countries; $A$ is a constant ; $Y$ represents the size of the national economy ; $D$ indicates the distance between the two countries.

Since this paper only uses the trade gravity model to study the unilateral flow problem of Chinese kiwifruit export, the basic form of the trade gravity model (1) is adjusted to obtain the adjusted basic form.:

$$
E X_{\mathrm{ij}}=\mathrm{A}\left(Y_{\mathrm{i}} Y_{\mathrm{j}}\right) / D_{\mathrm{ij}}
$$

(2) where $E X_{\mathrm{ij}}$ indicates the export volume of the exporting country $\mathrm{i}$ to the importing country $\mathrm{j} ; A$ is a constant; $Y_{\mathrm{i}}$ and $Y_{\mathrm{j}}$ represent the gross domestic product (GDP) of country i and country j, respectively; Usually in order to meet the requirements of linear estimation, you need to take the logarithm of both sides of (2), then:

$$
\ln E X_{\mathrm{ij}}=\beta_{0}+\beta_{1} \ln Y_{\mathrm{i}}+\beta_{2} \ln Y_{\mathrm{j}}+\beta_{3} \ln d_{\mathrm{ij}}+u_{\mathrm{ij}}
$$

We take the five-year data from 9 countries as samples, so we need to lengthen the observation period and use the long panel regression method to change (3) into:

$$
\ln E X_{i j}=\beta 0+\beta 1 \ln Y_{\mathrm{i}}+\beta_{2} \ln Y_{\mathrm{j}}+\beta_{3} \ln d_{\mathrm{ij}}+\beta_{4} \ln r_{\mathrm{i}}+\beta_{5} \ln b_{\mathrm{rij}}+u_{\mathrm{ij}}
$$

lower case. You should leave $35 \mathrm{~mm}$ of space above the title and $6 \mathrm{~mm}$ after the title. 


\section{Test sample}

Table 1. Total GDP of China and trading partner countries from 2000 to 2016

\begin{tabular}{|c|c|c|c|c|c|c|c|c|c|c|}
\hline \multicolumn{11}{|c|}{ Unit: tens of billions of dollars } \\
\hline Country & China & Kazakhstan & France & Indonesia & Spain & Malaysia & Canada & Germany & Thailand & Singapoe \\
\hline 2000 & 121.1 & 1.8 & 136.8 & 16.5 & 59.6 & 9.4 & 74.2 & 195.0 & 12.6 & 9.6 \\
\hline 2001 & 133.9 & 2.2 & 138.2 & 16.0 & 62.6 & 9.3 & 73.6 & 195.1 & 12.1 & 8.9 \\
\hline 2002 & 147.1 & 2.5 & 150.0 & 19.6 & 70.1 & 10.1 & 75.8 & 207.9 & 13.4 & 9.2 \\
\hline 2003 & 166 & 3.1 & 184.8 & 23.4 & 90.7 & 11.0 & 89.2 & 250.6 & 15.2 & 9.7 \\
\hline 2004 & 195.5 & 4.31 & 212.4 & 25.7 & 107 & 12.5 & 102.3 & 281.9 & 17.3 & 11.4 \\
\hline 2005 & 228.6 & 5.7 & 220.4 & 28.6 & 115.7 & 14.4 & 116.9 & 286.1 & 18.9 & 12.7 \\
\hline 2006 & 275.2 & 8.1 & 232.5 & 36.5 & 126.5 & 16.3 & 131.5 & 300.2 & 22.1 & 14.8 \\
\hline 2007 & 355.2 & 10.5 & 266.3 & 43.2 & 147.9 & 19.4 & 146.5 & 344.0 & 26.3 & 18.0 \\
\hline 2008 & 459.8 & 13.3 & 292.3 & 51.0 & 163.5 & 23.1 & 154.9 & 375.2 & 29.1 & 19.2 \\
\hline 2009 & 511 & 11.5 & 269.4 & 53.9 & 149.9 & 20.2 & 137.1 & 341.8 & 28.2 & 19.2 \\
\hline 2010 & 610.1 & 14.8 & 264.7 & 75.6 & 143.2 & 25.5 & 161.3 & 341.7 & 34.1 & 23.6 \\
\hline 2011 & 757.3 & 19.3 & 286.3 & 89.3 & 148.8 & 29.8 & 178.9 & 375.7 & 37.1 & 27.5 \\
\hline 2012 & 856.1 & 20.8 & 268.1 & 91.8 & 133.6 & 31.4 & 182.4 & 354.4 & 39.8 & 28.9 \\
\hline 2013 & 960.7 & 23.7 & 280.9 & 92.2 & 136.2 & 32.3 & 184.3 & 375.3 & 42.0 & 30.0 \\
\hline 2014 & 1048.2 & 22.1 & 283.9 & 89.0 & 137.6 & 33.8 & 179.3 & 387.9 & 40.4 & 30.6 \\
\hline 2015 & 1106.5 & 18.4 & 241.9 & 86.2 & 119.3 & 29.6 & 155.3 & 336.3 & 39.5 & 29.3 \\
\hline 2016 & 1180.6 & 18.6 & 245.0 & 90.5 & 123.1 & 30.8 & 157.5 & 342.7 & 40.9 & 29.9 \\
\hline
\end{tabular}

Table 2. The Distance between Beijing and the Capitals (economic centers) of Some Major Importers of Kiwifruit

\begin{tabular}{|c|c|c|}
\hline Country (region) & City & Distance (km) \\
\hline Kazakhstan & Astana & 3450 \\
\hline France & Paris & 9886 \\
\hline Indonesia & Jakarta & 5167 \\
\hline Spain & Madrid & 10361 \\
\hline Malaysia & Kuala Lumpur & 4318 \\
\hline Canada & Ottawa & 16875 \\
\hline Germany & Berlin & 8075 \\
\hline Thailand & Bangkok & 3088 \\
\hline Singapore & Singapore & 4281 \\
\hline
\end{tabular}

Data source: The straight line distance calculated from the googlearth map measurement.

Table 3. RMB real effective exchange rate index for 2000-2016

\begin{tabular}{|c|c|}
\hline Year & RMB annual real effective exchange rate index $(\boldsymbol{R})$ \\
\hline 2000 & 92.7617 \\
\hline 2001 & 98.3575 \\
\hline 2002 & 98.0858 \\
\hline 2003 & 91.8242 \\
\hline 2004 & 87.4858 \\
\hline 2005 & 87.0775 \\
\hline
\end{tabular}




\begin{tabular}{|l|c|}
\hline 2006 & 89.0417 \\
\hline 2007 & 90.1425 \\
\hline 2008 & 96.1642 \\
\hline 2009 & 102.0025 \\
\hline 2010 & 99.9992 \\
\hline 2011 & 100.1933 \\
\hline 2012 & 105.9234 \\
\hline 2013 & 111.8717 \\
\hline 2014 & 114.7108 \\
\hline 2015 & 125.6467 \\
\hline 2016 & 119.9108 \\
\hline
\end{tabular}

Table 4. All major kiwifruit importing countries and China signed the "One Belt, One Road" cooperation agreement Statistical table

\begin{tabular}{|c|c|c|c|c|c|c|c|c|c|}
\hline Country & Haskstan & France & Indonesia & Spain & Malaysia & Canada & Germany & Thailand & Singapoe \\
\hline 2000 & 0 & 0 & 0 & 0 & 0 & 0 & 0 & 0 & 0 \\
\hline 2001 & 0 & 0 & 0 & 0 & 0 & 0 & 0 & 0 & 0 \\
\hline 2002 & 0 & 0 & 0 & 0 & 0 & 0 & 0 & 0 & 0 \\
\hline 2003 & 0 & 0 & 0 & 0 & 0 & 0 & 0 & 0 & 0 \\
\hline 2004 & 0 & 0 & 0 & 0 & 0 & 0 & 0 & 0 & 0 \\
\hline 2005 & 0 & 0 & 0 & 0 & 0 & 0 & 0 & 0 & 0 \\
\hline 2006 & 0 & 0 & 0 & 0 & 0 & 0 & 0 & 0 & 0 \\
\hline 2007 & 0 & 0 & 0 & 0 & 0 & 0 & 0 & 0 & 0 \\
\hline 2008 & 0 & 0 & 0 & 0 & 0 & 0 & 0 & 0 & 0 \\
\hline 2009 & 0 & 0 & 0 & 0 & 0 & 0 & 0 & 0 & 0 \\
\hline 2010 & 0 & 0 & 0 & 0 & 0 & 0 & 0 & 0 & 0 \\
\hline 2011 & 0 & 0 & 0 & 0 & 0 & 0 & 0 & 0 & 0 \\
\hline 2012 & 0 & 0 & 0 & 0 & 0 & 0 & 0 & 0 & 0 \\
\hline 2013 & 0 & 0 & 0 & 0 & 0 & 0 & 0 & 0 & 0 \\
\hline 2014 & 1 & 0 & 1 & 0 & 0 & 0 & 0 & 0 & 0 \\
\hline 2015 & 1 & 0 & 1 & 0 & 1 & 0 & 0 & 1 & 0 \\
\hline 2016 & 1 & 0 & 1 & 0 & 1 & 0 & 0 & 1 & 0 \\
\hline
\end{tabular}

Data source: The national "One Belt, One Road" official website policy inquiry, 0 indicates that the country (region) has not signed a cooperation agreement with China, and 1 indicates that the country (region) has signed a cooperation agreement in China.

\section{Results and discussion}

\subsection{The correlation test}

Table 5. Explain the correlation between variables

\begin{tabular}{|c|c|c|c|c|c|}
\hline & $\ln \boldsymbol{Y}_{\mathbf{i}}$ & $\ln \boldsymbol{Y}_{\mathbf{j}}$ & $\ln \boldsymbol{d}_{\mathbf{i j}}$ & $\ln \boldsymbol{r}_{\mathbf{i}}$ & $\ln \boldsymbol{b} \boldsymbol{r}_{\mathbf{i}}$ \\
\hline $\ln Y_{\mathrm{i}}$ & 1.0000 & $0.3253^{*}$ & 0.0000 & $0.7890^{*}$ & $0.3033^{*}$ \\
\hline $\ln Y_{\mathrm{j}}$ & $0.3253^{*}$ & 1.0000 & $0.7633^{*}$ & $0.2054^{*}$ & -0.0822 \\
\hline $\ln d_{\mathrm{ij}}$ & 0.0000 & $0.7633^{*}$ & 1.0000 & 0.0000 & $-0.1737^{*}$ \\
\hline $\ln r_{\mathrm{i}}$ & $0.7890^{*}$ & $0.2054^{*}$ & 0.0000 & 1.0000 & $0.4092^{*}$ \\
\hline $\ln b r_{\mathrm{i}}$ & $0.3033^{*}$ & -0.0822 & $-0.1737^{*}$ & $0.4092^{*}$ & 1.0000 \\
\hline
\end{tabular}


It can be seen from Table 5 that the correlation between most of the variables in the original model is low, and there is only a strong correlation between the individual explanatory variables. If the correlation coefficient between China's total economic outputs and the effective exchange rate of $\mathrm{RMB}$ is 0.7890 , the correlation coefficient between Beijing and the trading partners is 0.7633 , showing a strong correlation, and there is no obvious correlation between other data.

\subsection{Hausmann test}

Table 6. Hausmann test results

\begin{tabular}{|c|c|c|c|c|}
\hline & $(\mathbf{b})$ & $(\mathbf{B})$ & $(\mathbf{b}-\mathbf{B})$ & sqrt \\
\hline & fixed & random & Difference & S.E. \\
\hline $\ln Y_{\mathrm{i}}$ & 0.219715 & 0.672254 & -.452539 & 0.418093 \\
\hline $\ln Y_{\mathrm{j}}$ & 0.481485 & -.158887 & 0.640372 & 0.589583 \\
\hline $\ln r_{\mathrm{i}}$ & -1.503734 & -2.703973 & 1.200239 & 1.192002 \\
\hline $\ln b r_{\mathrm{i}}$ & 0.985230 & 1.163412 & -.1781821 & 0.287111 \\
\hline
\end{tabular}

Through the Hausmann test, we use the fixed effect or the random effect. The test results show that the original hypothesis is that each fixed effect is the same, refusal chooses the fixed effect, and vice versa chooses the random effect better. The $\mathrm{P}$ value is 0.8304 . Accept the null hypothesis.

\subsection{B-P test}

The B-PLM-test test results show that it is better to choose a mixed OLS model.

Table 7. BPLM test results

\begin{tabular}{|c|c|c|}
\hline & Var & sd=sqrt(Var) \\
\hline $\ln E X_{\mathrm{ij}}$ & 3.051726 & 1.746919 \\
\hline $\mathrm{e}$ & 2.641545 & 1.625283 \\
\hline $\mathrm{u}$ & 0.1400772 & 0.3742688 \\
\hline
\end{tabular}

\subsection{Extended gravitational model estimation}

In this paper, the regression results of the mixed OLS effect model, fixed effect model and random effect model using panel data were compared. The latter two have not passed the model test. Therefore, the mixed OLS effect model is used for empirical analysis. The regression results are shown in Table 8.

Table 8. Regression results of kiwifruit export gravity model

\begin{tabular}{|c|c|}
\hline Explanatory vriables & Basic equation \\
\hline Constant term & $\begin{array}{c}23.2039 \\
(2.6300)\end{array}$ \\
\hline $\ln Y_{\mathrm{i}}$ & $\begin{array}{l}0.7073 * * \\
(2.3100)\end{array}$ \\
\hline $\ln Y_{\mathrm{j}}$ & $\begin{array}{c}-0.2099 \\
(-1.1100)\end{array}$ \\
\hline $\ln d_{\mathrm{ij}}$ & $\begin{array}{c}-0.4418 \\
(-1.0500)\end{array}$ \\
\hline $\ln r_{\mathrm{i}}$ & $\begin{array}{c}-2.7393 \\
(-1.2900)\end{array}$ \\
\hline $\ln b r_{\mathrm{i}}$ & $\begin{array}{c}1.1130^{*} \\
(1.6600)\end{array}$ \\
\hline adjusted $R^{2}$ & 0.1087 \\
\hline F statistics & 4.7100 \\
\hline
\end{tabular}

Note: $* *$ represents a $5 \%$ significance level; * represents a $10 \%$ significance level. The $t$ statistics are in parentheses. 
Based on the above regression results, we get the final adjustment equation (4) as follows:

$$
\begin{gathered}
\ln E X_{\mathrm{ij}}=23.2039+0.7073 \ln Y_{\mathrm{i}}-0.2099 \ln Y_{\mathrm{j}}-0.4418 \ln d_{\mathrm{ij}} \\
-2.7393 \ln r_{\mathrm{i}}+1.1130 \ln b r_{\mathrm{iI}}
\end{gathered}
$$

\subsection{Gravity model results analysis}

The results indicate that: (a) National GDP has a significant impact on kiwifruit exports, indicating that kiwifruit exports are positively correlated with GDP, the same as expected. (b) The regression results of kiwifruit export volume and geographical distance is negative and not significant, indicating that the export of kiwifruit has nothing to do with the geographical distance between the two countries, which is not in line with expectations. The reason is that with the rapid development of the transportation industry, the cold chain transportation preservation technology is mature, and the geographical distance is no longer the main factor hindering the export of kiwifruit. Therefore, the geographical distance has no significant effect on the export of kiwifruit. (c) The actual effective exchange rate is negatively correlated but not actual, and is consistent with the expected symbol but not significant. Therefore, the price in the kiwifruit trade is not a significant factor affecting the trade volume. It is the commercial way to improve the cultivation and management level of kiwifruit. (d) Institutional policies have a certain role in promoting the export of kiwifruit, which is the same as the expected symbol. It shows that kiwifruit export is affected by the institutional arrangement of reducing trade transaction costs. The relevant agreements are conducive to trade facilitation and promote the free flow of trade between member countries.

\section{Conclusion}

Through the analysis of the trade gravity model, the main factors affecting the export of kiwifruit are the economic model (GDP) and institutional arrangements of trading partners. Therefore, the European and American markets are the main potential countries for kiwifruit export. We need to fully tap the potential of kiwifruit in the European and American markets and promote kiwifruit trade and development.

\section{References}

1. Zhang Meng, Zhang Zongyi. China's agricultural machinery products export trade flow and potential [J]. International Trade Issues. 2015; 6: 148-154.

2. Jiang Guan, Huo Qiang. Trade creation effect and trade potential of China-ASEAN free trade areaan empirical analysis based on panel data of gravity model [J]. Contemporary Economic Management. 2015; 02: 60-67

3. Yin Mei. Re-test of RMB exchange rate changes, export trade and its influencing factors [J]. Journal of Nantong University (Social Science Edition). 2013; 03: 123-127

4. Fang Ying, Ma Wei. The sultural trade potential and influencing factors of china along the belt and road initiative: an empirical study based on stochastic frontier gravity model $[\mathrm{J}]$. World Economic Research. 2018; 01: 121-136

5. Wu Lizhen, Xie Shuhua. International trade of agricultural products under the background of the "belt and road" strategy [J]. Anhui Agricultural Sciences. 2016; 02: 266-268.

6. Xu Guangling, Meng Yuqing, Yan Sulan. Research on the development of agricultural products trade between China and central Asian countries under the "belt and road" strategy [J]. World economic research. 2017; 33(04): 154-157.

7. Jin Jinliang. Problems and development strategies of kiwifruit industry in China [J]. World economic research. 2015; (04): 521-529.

8. Li Zhenghui, Peng Yu, Tang Wei. Jerry Hausman's contribution to applied econometrics [J]. Economics Dynamics. 2016; 11: 148-158.

9. Huo Lian Cai, Yang Chao, Li Ya Feng. Research on the correlation between air freight and regional economic development based on OLS [J]. Journal of Chifeng University ( Natural Science Edition ). 2018; 1(34): 61-63.

10. Gao Hongye. The fifth edition of the microscopic part of Western economics [M]. Journal of Chifeng University ( Natural Science Edition ). 2018; 28-44.

11. Zhang Jinyan, You Qianqian. Analysis of the factors affecting China's agricultural products trade deficit to ASEAN [J]. Journal of Jiujiang University ( Social Science Edition ). 2017; 1: 119-124.

12. Li Qin. An empirical test of trade gravity model on trade flows between China's Xinjiang and central Asian countries and analysis of export potential [J]. Reform and Strategy. 2008; 11: 215-218.

13. Gu Kejian. Development and application of trade gravity model by international economics $[\mathrm{J}]$. World Economy. 2001; (02): 14-25.

14. Jiang Shuzhu, Zhang Xukun. The gravitational model of ASEAN trade effect [J]. Quantitative Economics and Economics Research. 2003; (10): 55-59.

15. Li Yabo. A Study on the Potential of Bilateral Goods Trade between China and Chile Based on Gravitational Model Empirical Analysis of Type I $[\mathrm{J}]$. Exploration of International Economy and Trade, 2013 (7): 62-69.

16. Cheng Weijing, Feng Fan. Trade Effect of ChinaASEAN Free Trade Area: Based on the Third Order Empirical Analysis of Duan Gravity Model [J]. Exploration of International Economic and Trade, 2014 (2) : 4-16. 